\title{
PHYSICAL MODELLING SIMILITUDE : A STUDY OF SEDIMENT DEPOSITION IN RESERVOIR
}

(Date received: $14.01 .2020 /$ Date accepted: 29.06 .2020$)$

\author{
Safari Mat Desa ${ }^{*}$, Mohd Kamarul Huda Samion', Mohd Hidayat Jamal², \\ Ahmad Farhan Hamzah', Ernie Abd Manan', Saiful Bahri Hamzah ${ }^{1}$, Md Nasir Md Noh ${ }^{1}$ \\ ${ }^{1}$ National Hydraulic Research Institute of Malaysia, Selangor Darul Ehsan, Malaysia \\ ${ }^{2}$ School of Civil Engineering, University Technology Malaysia \\ *safari@nahrim.gov.my
}

\section{ABSTRACT}

Changes in rainfall pattern, rapid urbanization, infrastructure development and uncontrolled agricultural activities have been found as major sources to contribute to excessive reservoir sedimentation problem in Malaysia, thus significantly shorten the design life of a reservoir. Hence, reservoir functions have deteriorated, such as reduction in power generation capacity, additional lateral load affected to dam stability and decrease in storage capacity for flood control. The objective of this study is to model, simulate and propose alternative method for sediment removal control in Ringlet Reservoir. The construction of physical model of Ringlet Reservoir took place in the Hydraulic and Instrumentation Laboratory, National Hydraulic Research Institute of Malaysia (NAHRIM), with geometric similitude of 1:30. Three different average recurrent intervals (ARI) of 1, 5 and 100 were tested at Sungai Habu and Ringlet. Groyne was identified as a control mitigation structure for sediment control, and a total of 23 groynes were constructed. Physical modelling execution explicitly showed the gross deposition and erosion is linear as the return period rose. Bed sediment for a 100 year ARI was eroded more than that of 1 and 5 year ARI, due to local scour resulting from the flow transition from fixed bed to mobile bed.

At Ringlet, sediment was deposited mostly before the first check dam for 1 year ARI. For 5 and 100 ARI, sediment was further transported before the second check dam. Finding in Habu, showed morphological changes was due to the local flow. The movement of bed sediment at the end of Habu, were deposited much early before the check dam, thus not travelling further downstream. Geometrical similitude of this modelling was carried out successfully, and gained recognition from the Malaysia Book of Records as the Biggest Hydraulic Model.

\subsection{INTRODUCTION}

Ringlet reservoir is located at Sungai Bertam in the mukim of Ringlet, Cameron Highlands district of Pahang, Malaysia [1,2]. During monsoon, a massive volume of discharge flow had instigated an uncommon increased of water level in Sungai Bertam. The reservoir has been experiencing excessive sedimentation problem for years. The problem originated from widespread soil erosion caused by changes in rainfall pattern, rapid urbanization, infrastructure development and uncontrolled agricultural activities. Researches by Adeogun [3] and Bussi [4] found that sedimentation that happened due to deforestation and natural vegetation removal on the upstream of a catchment would ultimately flow into the dam and settled at the bottom of the dam. In the course of time, the cummulative volume of sediment will affect the dam water level. This will cause the water level of the dam to increase [5]. Escalation in sediment deposition rate leads to the approximate useful life of the reservoir deteriorates significantly. This also reduces the reservoir power generation capacity and dangerously affects dam stability and flood control storage. Recently, in July 2019, the Tiware dam in Ratnagiri district, India, ruptured due to heavy rains. The accidents related to dam such as dam break or uncontrolled amount of water discharge is due to a high level of energy [6]. Dredging operations have been implemented since early commissioning of the dam to maintain adequate reservoir storage volume. However, with an increase in the sediment deposition rate, the dredging volume has increased tremendously and is expected to increase even further in the near future and implicate a lot to operational cost. The objective of this study is to model, simulate and propose alternative method for efficient sediment removal in Ringlet reservoir.

\subsection{METHOD OF SIMILITUDE FOR PHYSICAL MODEL DESIGN}

A physical model is the study of actual system on smaller scale. In order to obtain the closes representation of the actual system, the physical model needs to fulfill the similitude criteria.

\subsection{Dynamic Similitude}

Dynamic similarity makes it possible to scale results from model tests to predict corresponding results for the full-scale prototype. Dynamic similarity can be obtained by matching the ratio of several important forces acting on the system. For hydraulic system, these ratios are given by the Reynolds (Re) and Froude (Fr) numbers. Reynolds number is the ratio between inertial and viscous forces while Froude number is the ratio between inertial to gravitational forces. These ratios or dimensionless numbers are given by Equations 1 and 2. 


$$
\begin{aligned}
& \mathrm{Re}=\frac{u D}{v} \\
& \mathrm{Fr}=\frac{u}{\sqrt{g D}}
\end{aligned}
$$

where $u$ is the fluid velocity, $D$ is the flow depth, $v$ is the fluid kinematic viscosity and $g$ is the gravity. Froude scaling is usually adopted for free surface flow as gravitational force is more dominant than viscous force. The scaling effect (from the Reynolds number mismatched) can be significantly reduced if turbulent flow condition exists.

\subsection{Geometric and Kinematic Similitude}

An undistorted model is used in this physical model study. This means that the horizontal (X), lateral (Y) and vertical $(\mathrm{Z})$ axes scales are similar as in Equation 3.

$$
X_{\lambda}=Y_{\lambda}=Z_{\lambda}
$$

The subscript $\lambda$ is the geometric ratio between the prototype and model given by Equation 4.

$$
\lambda=\frac{L_{\mathrm{p}}}{L_{\mathrm{m}}}
$$

where $L$ is reference length for the prototype, $p$, and the physical model, $m$. Based on the Froude scaling, important hydraulic parameters will be scaled as in Equations 5 to 7.

$$
\begin{array}{cl}
\text { Velocity }(u) & \frac{u_{p}}{u_{m}}=\lambda^{\frac{1}{2}} \\
\text { Discharge }(Q) & \frac{Q_{p}}{Q_{m}}=\lambda^{\frac{5}{2}} \\
\text { Time }(t) & \frac{t_{p}}{t_{m}}=\lambda^{\frac{1}{2}}
\end{array}
$$

\subsection{Sediment Transport Similitude}

For sediment transport, particle movement is a function of drag force and the resisting force that keep the particle in place. To obtain correct particle movement between the prototype and physical model, the sediment size need to be scaled based on the dimensionless shear stress or Shield parameter, $\tau_{-}$and grain Reynolds number, $R e_{m}$. These are given as in Equations 8 and 9.

$$
\begin{aligned}
& \tau_{v}=\frac{\tau_{0}}{\left(\gamma_{s}-\gamma\right) d_{s}} \\
& R_{e}=\frac{u, d_{s}}{v}
\end{aligned}
$$

where $\tau_{a}$ is the bed shear, $\gamma_{s}-\gamma$ is the buoyant specific weight, $d_{s}$ is the particle size and $u_{*}$ is the shear velocity. Based on these scaling, the following sediment transport parameters can be calculated using Equations 10 and 11.

$$
\begin{array}{ll}
\text { Particle size } & \left(\frac{d_{m}}{d_{p}}\right)^{3}=\frac{\left(\rho_{s}-\rho\right)_{p}}{\left(\rho_{s}-\rho\right)_{m}} \\
\text { Sediment } & \frac{t_{s p}}{t_{s m}}=\lambda^{\frac{1}{2}} \frac{\left(\rho_{s}-\rho\right)_{p}}{\left(\rho_{s}-\rho\right)_{m}} \\
\text { time ( } \left.t_{s}\right) &
\end{array}
$$

\subsection{METHODOLOGY}

\subsection{General Considerations}

This physical model study was required to satisfy the proposed structures in the Ringlet Reservoir - simulation with first groyne orientation.

\subsection{Sediment Selection}

A moveable bed model was used to study the movement of sediment in the critical part of the reservoir. A movable-bed model is a model where part of the bed is composed of particles that can be transported by the hydrodynamics forces of the flow. In order to scale the prototype sediment, four materials are considered. These are sand (similar to prototype), Bakelite, ABS and wood dust flour (or saw dust). To achieve sediment similitude, the model sediment need to be scaled. The scaling can be done by appropriate selection of the density and diameter of the model material. Table 1 shows the diameter and density of prototype sediment. Meanwhile, Table 2 presents the density of several model sediments.

Table 1: Diameter and density of prototype sediment

\begin{tabular}{lcc}
\hline & Bed Load & Note \\
\hline Diameter $[\mathrm{mm}]$ & 1.5 & Average particle size (D $\left(_{50}\right)$ \\
\hline Density $\left[\mathrm{kg} / \mathrm{m}^{3}\right]$ & 2650 & \\
\hline
\end{tabular}

Table 2: Diameter and density of prototype sediment

\begin{tabular}{ccccc}
\hline & Sand & Bakelite & ABS & Wood flour \\
\hline Density $\left[\mathrm{kg} / \mathrm{m}^{3}\right]$ & 2650 & 1300 & 1220 & 1100
\end{tabular}

Based on the densities of the model sediments, the appropriate sediment diameter can be determined by matching the dimensionless shear stress and Grain Reynolds number between the prototype and model sediments.

\subsection{Scenario Flow Rates and Sediment Load}

Based on preliminary study, the maximum flow rates and the

\begin{tabular}{|c|c|c|c|}
\hline & ARl (years) & Model Alow nate. Q(1/s) & Sediment lood $Q \mathrm{gkg} \mathrm{hr})$ \\
\hline \multirow[t]{3}{*}{ Habu } & 1 & 4.7 & 2.1 \\
\hline & 5 & 7.0 & 32 \\
\hline & 100 & 113 & 5.1 \\
\hline \multirow[t]{3}{*}{ Ringlet } & 1 & 1.5 & 1.1 \\
\hline & 5 & 2.7 & 1.7 \\
\hline & 100 & 4.6 & 2.4 \\
\hline
\end{tabular}
corresponding sediment loads for prototype, corresponding to various storm return periods were tested in the physical model are presented in Table 3. As for the physical model, the scaleddown average flow rates and sediment loads are given as in Table 4.

Table 3: Maximum prototype flow rates, $Q$ and sediment loads, Qs for Habu and Ringlet ends

\begin{tabular}{lccc}
\hline & ARI (ycars) & Flow rats. Q (m/s) & Sodiment load. Q.Akg hr) \\
\hline Habu & 1 & 23.5 & 226059 \\
\cline { 2 - 4 } & 5 & 34.5 & 243597 \\
\cline { 2 - 4 } & 100 & 55.5 & 267209 \\
\hline \multirow{3}{*}{ Ringlet } & 1 & 7.5 & 91373 \\
\cline { 2 - 4 } & 5 & 13.4 & 134588 \\
\cline { 2 - 4 } & 100 & 23.0 & 193005 \\
\hline
\end{tabular}

Table 4: Scaled-down model average flow rates, $Q$ and sediment loads, Qs for Habu and Ringlet ends based on different return period

\subsection{Physical Model Construction}

The construction of physical sediment removal model of Ringlet Reservoir took place in the Hydraulic and Instrumentation Laboratory, National Hydraulic Research Institute of Malaysia (NAHRIM). The model was constructed with a geometric scale 
of 1:30. The layout plans of the physical model design are shown in Figures 3.

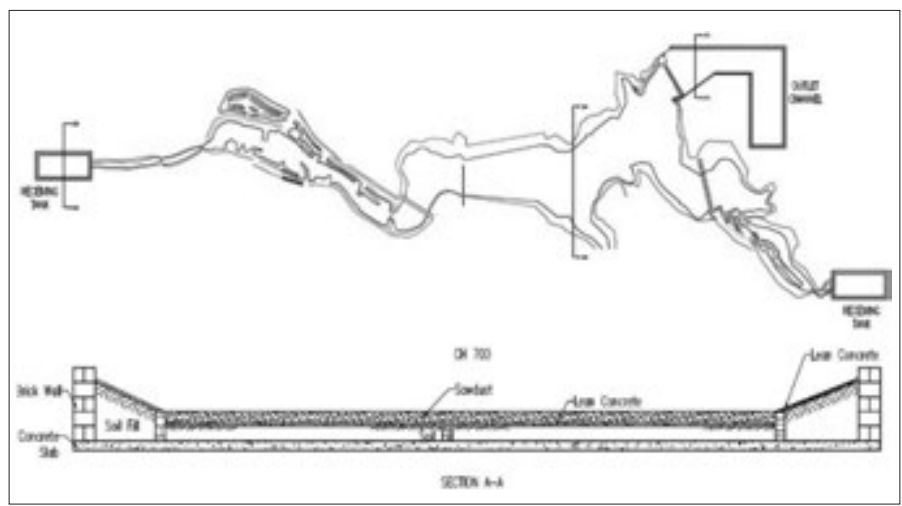

Figure 3: Physical model layout plan and cross-sections

\subsection{Sampling Procedure}

Data collected in the study were sediment bed profile change, water velocity and water velocity distribution. The measurements were carried out prior to the experiment, during experiment and after the completion of experiment. The experimental procedures adopted in this study are described as follows:

The sediment bed was contoured based on the initial profile which was the level before performing any test. The sediment bed before any test was measured and recorded. Water was filled up until maximum level of the model, and the flow rate was consistent for both 1 and 5 years ARI during the measurements. Meanwhile, separable flow rate for 100 years ARI was changed into the designated flow rate based on the Table 4 .

\subsection{RESULT AND DISCUSSION}

This section mainly presents the results of physical modelling study on sediment removal model of Ringlet Reservoir. Sungai Habu and Sungai Ringlet were tested up to three different ARI which are 1 year ARI, 5 years ARI and 100 years ARI. The data collected from the model were bed profiles and flow velocity at selected chainages for both Habu and Ringlet ends. Figure 4 show grid meshes of $25 \mathrm{~cm}$ marked on each chainages of model bed to record the changes of bed profile either deposition or erosion of sediment.

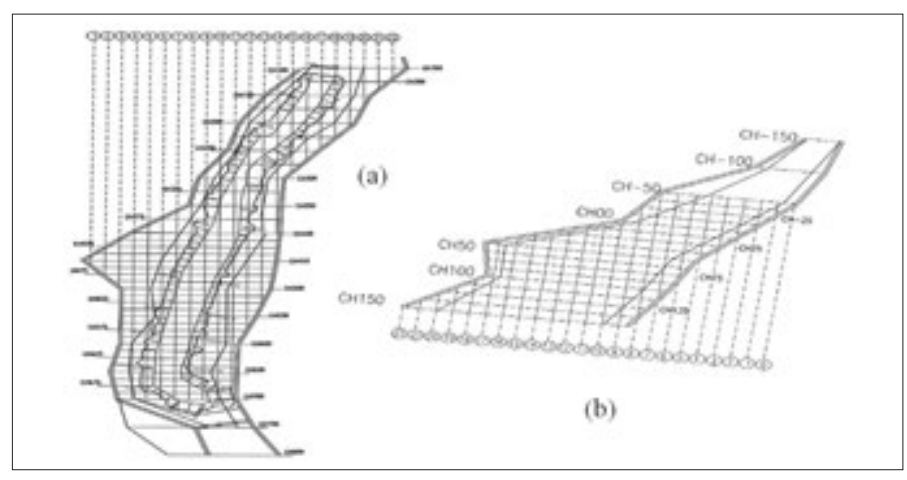

Figure 4: Grid meshes at (a) Habu and (b) Ringlet end

\subsection{Habu Bed Profiles}

Figures 5 to 7 illustrates the outcome of erosion and deposition of 1, 5 and 100 years ARI at Habu. The observed bed morphology at $\mathrm{Habu}$ in this section only covers 3 selected chainages which are $\mathrm{CH} 700, \mathrm{CH} 400$ and $\mathrm{CH}$ 150. As shown in Figure 5 to 7, it can be seen that there is slightly higher erosion at $\mathrm{CH} 700$ due to the local scour occurred which is caused by interchange between the fix and mobile bed. There is not much difference between the pre and post measurements for $\mathrm{CH} 400$ and $\mathrm{CH} 150$ for 1,5 and 100 years ARI.

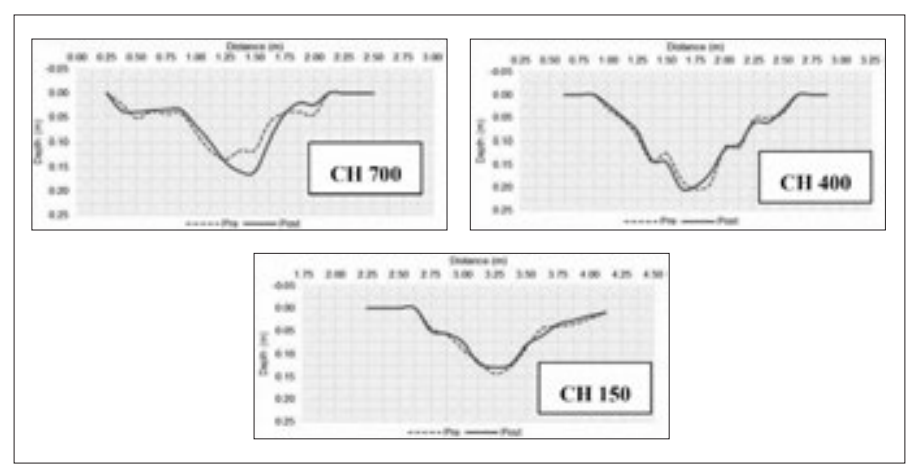

Figure 5: Cross-section of selected chainages for 1ARI at Habu

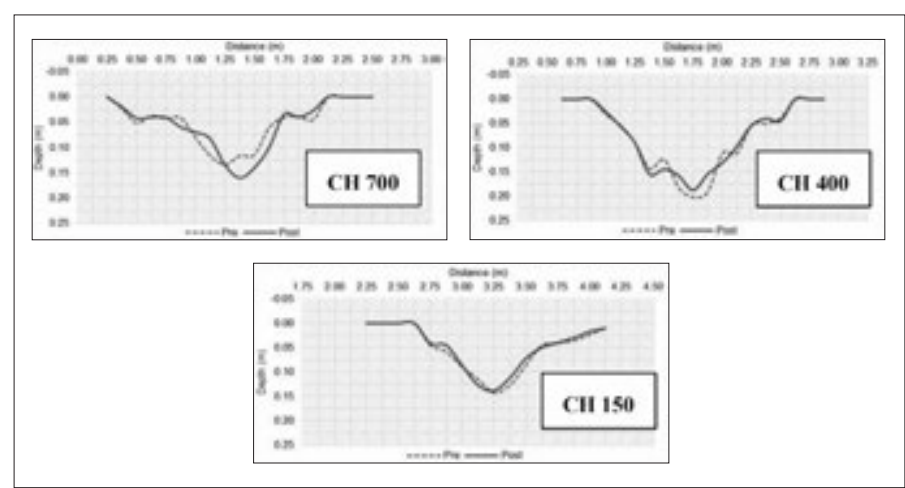

Figure 6: Cross-section of selected chainages for 5ARI at Habu

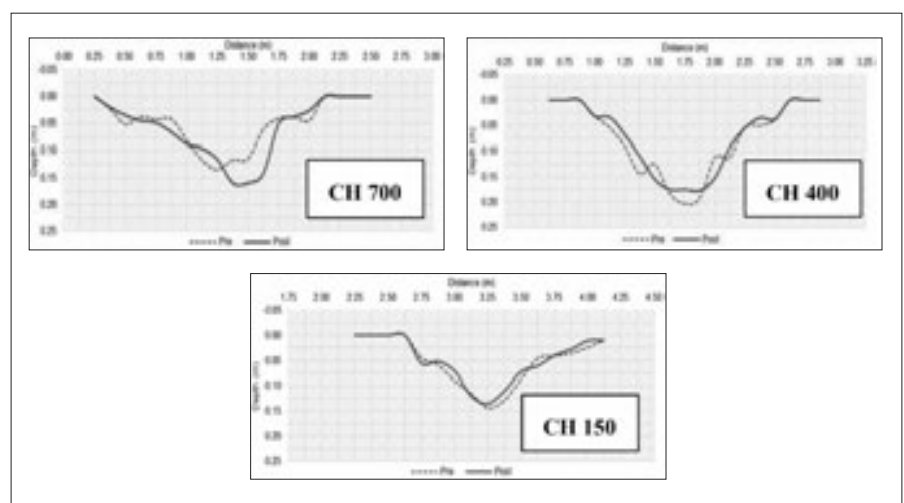

Figure 7: Cross-section of selected chainages for 100 ARI at Habu

\subsection{Ringlet Bed Profiles}

In $\mathrm{CH}-37.5$ for 1,5 and 100 years ARI, it can be seen that the major process occurring is erosion as sediment is flush into the channel because of local scouring occurring at the bed along the chainage (Figures 8 to 10). As for $\mathrm{CH} 25$, it can be seen that the deposition and erosion of sediment occurred at 1, 5 and 100 ARI. A 1 year ARI has more sedimentation occurring at the middle and right bank of $\mathrm{CH} 25$, whereas a 5 years ARI has only deposition but no erosion happened across the chainage. As for 100 years ARI, more erosion is found at the flow channel than deposition at the left bank. On the other hand, $\mathrm{CH} 87.5$ does not show much difference in all three ARI's except with slightly higher erosion at 5 years ARI. 


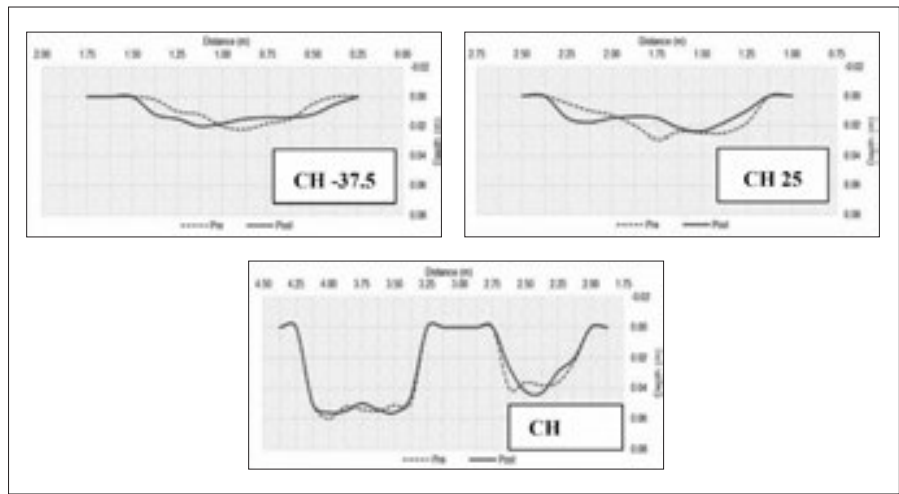

Figure 8: Cross-section of selected chainages for 1ARI at Ringlet

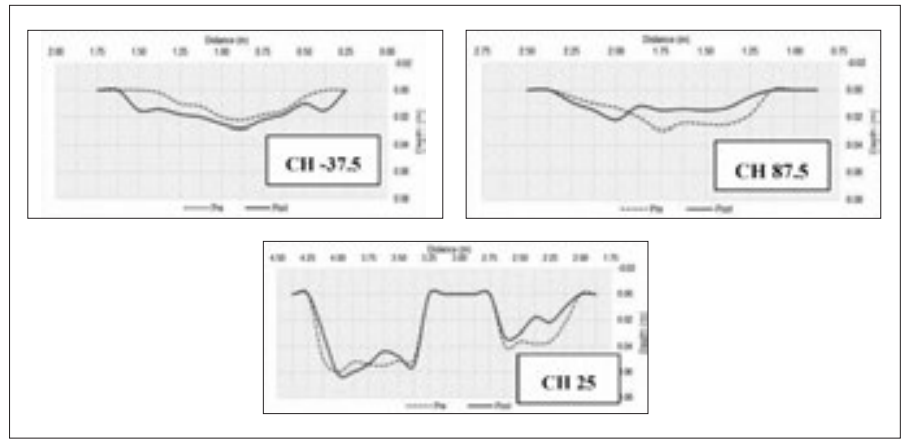

Figure 9: Cross-section of selected chainages for 5ARI at Ringlet

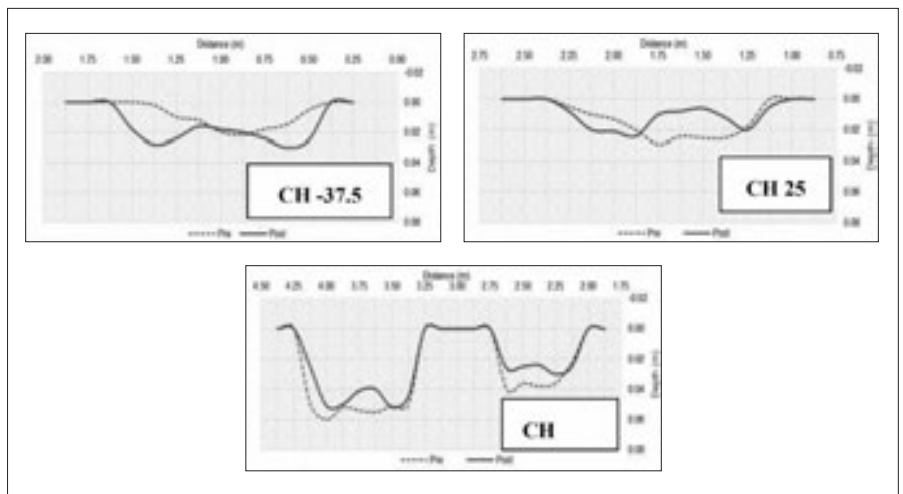

Figure 10: Cross-section of selected chainages for 100ARI at Ringlet

\subsection{Bed Morphological Changes}

During the experiment, the bed profile for every chainage was recorded before and after each test to observe the sediment movement pattern. It can be seen that the quantity of deposited bed load at Habu and Ringlet end were increased as the return period increased. For instance, the gross volume due to erosion at Habu end is $\quad-0.1349 \mathrm{~m}^{3},-0.1590 \mathrm{~m}^{3}$, and $-0.1815 \mathrm{~m}^{3}$ for 1,5 and 100 years ARI, respectively. However, the gross deposition volume at the Habu end for 1, 5 and 100 years ARI are 0.1516 $\mathrm{m}^{3}, 0.1856 \mathrm{~m}^{3}$ and $0.2255 \mathrm{~m}^{3}$, respectively. At Ringlet end, the gross volume of due to erosion is $-0.0234 \mathrm{~m}^{3},-0.0296 \mathrm{~m}^{3}$ and $-0.0343 \mathrm{~m}^{3}$ for 1,5 and 100 years ARI, respectively. Meanwhile, the total volume of deposit bed sediment at Ringlet end are $0.0247 \mathrm{~m}^{3}, 0.0335 \mathrm{~m}^{3}$ and $0.0451 \mathrm{~m}^{3}$, respectively.

\subsection{CONCLUSION}

Finding showed that the gross deposition and erosion areas increased as the return period rose. Sediment mostly carries up to $\mathrm{CH} 575$ for 1 and 5 years ARI. However, for 100 years ARI, sediment may be carried further up to $\mathrm{CH} 475$. Then, the morphological changes occurred at Habu is due to the local flow. The movement of bed sediment at Habu end will be deposited before the check dam, and will not travel further downstream. For Sungai Ringlet, more erosion is found at the flow channel than deposition at the left bank for 100 years ARI. As a recommendation, further study should be implemented by widening and deepening both of Sungai Habu and Ringlet, as well as constructing additional groynes at designated chainages.

\section{ACKNOWLEDGEMENT}

The authors acknowledge the TNB Research Sdn. Bhd. for providing a grant for this project, Angkasa Counsulting Services Sdn. Bhd., Universiti Teknologi Malaysia (UTM), and Makmal Hidraulik dan Instrumentasi, National Hydraulic Research Institute of Malaysia (NAHRIM) for the tremendous hard work and team spirit in this modelling execution.

\section{REFERENCES}

[1] Lariyah M.S, Faizah C.R., Mohd Noh, A., Rahsidi S. M., Azwin Zailti, A. R., Mohd Nor, M.D., Hidayah B. \& Intan Shafilah A.A, 2012, Development of Probable Maximum Flood (PMF) for Sultan Abu Bakar, 5th Engineering Conference.

[2] Siti Multazimah Mohamad Faudzi, Ismail Abustan, Muhammad Azraie Abdul Kadir, Muhammad Khairi A.Wahab and Mohd Firdaus Abdul Razak, Two-Dimensional Simulation of Sultan Abu Bakar Dam Release Using HEC-RAS, International Journal of GEOMATE, June 2019, Vol.16, Issue 58, pp.124 - 131.

[3] Adeogun, A. G., Sule, B. F., Salami, A. W., (2015), Simulation Of Sediment Yield At The Upstream Watershed Of Jebba Lake In Nigeria Using Swat Model, Malaysian Journal of Civil Engineering, Vol 27(1), pp. 25-40.

[4] Bussi, G., Lloveras, X. R., Frances, F., Benito, G., Moya, Y. S., Sopena, A., (2013), Sediment Yield Model Implementation Based On Check Dam Infill Stratigraphy In A Semiarid Mediterranean Catchment, Hydrology and Earth System Sciences, Vol 17, pp. 3339-3354, DOI: 10.5194/hess-17-3339.

[5] Kondolf, G. M., Gao, Y., Annandale, G. W., Morris, G., L., Jiang, E., Zhang, J., Cao, Y., Carling, P., Fu, K., Guo, Q., Hotchkiss, R., Peteuil, C., Sumi, T., Wang, H. W., Wang, Z., Wei, Z., Wu, B., Wu, C., Yang, C. T., (2014), Sustainable Sediment Management In Reservoirs And Regulated Rivers: Experiences From Five Continents, Earth's Future, Vol 2, pp. 256-280, DOI : 10.1002/2013EF000184.

[6] Sidek, L. M., Ros, F. C., Aziz, N. H. A., (2011), Numerical Modelling of Dam Failure for Hydropower Development in Cameron Highlands - Batang Padang Scheme, Pahang Malaysia, Student Conference on Research International Journal of GEOMATE, June 2019, Vol.16, Issue 58, pp.124 - 131131 and Development.Author H., A Book New York Publisher, Year, pp.1-200. 


\section{PHYSICAL MODELLING SIMILITUDE : A STUDY OF SEDIMENT DEPOSITION IN RESERVOIR}

\section{PROFILES}

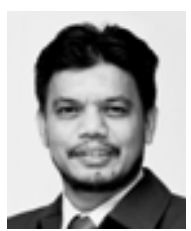

Ir. DR SAFARI HJ. MAT DESA currently serves as Director of River Basin Research Centre in National Hydraulic Research Institute of Malaysia (NAHRIM). He obtained his PhD Civil Engineering and Structure from UKM in the research of Coastal Hydrodynamic Physical Modelling. Actively involved in physical modelling, he was granted for professional industrial attachment in HR Wallingford UK and engaged in a big scheme modelling particularly for coastal rock cliff in UK and hydrodynamic thermal outflow in Saudi. He is a Professional Engineer with Practising Certificate from the Board of Engineer Malaysia, Corporate Member to Institution of Engineer Malaysia and Asean Chartered Professional Engineer.

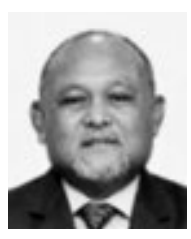

DATO' Ir. DR HJ. MD. NASIR BIN MD NOH is a Civil Engineer by profession and have served within the Drainage and Irrigation Department of Malaysia for more than 30 years. He obtained his Bachelor degree in Civil Engineer from Louisiana State University, USA, and Masters and $\mathrm{PhD}$ degrees from the Tottori University, Japan.

Currently, Dato' Ir. Dr Hj. Md. Nasir is the Director General of National Hydraulic Research Institute of Malaysia (NAHRIM). He is a certified professional in Erosion and Sediment Control and has served as technical advisory panel and expert panel in various technical working groups and professional bodies. He is the vice chairman of the Network of Asian River Basin Organization (NARBO), Jakarta and a Management Committee Member of the Board of Engineers, Malaysia.

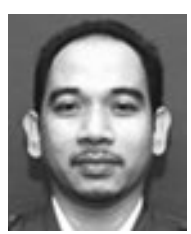

SAIFUL BAHRI HAMZAH received his master of science in environment at University Putra Malaysia in 2009. He has been serving National Hydraulic Research Institute of Malaysia (NAHRIM) since 1999. At NAHRIM, he holds the position of senior research officer in Hydraulic and Instrumentation Laboratory. He is currently the head researcher in charge of hydraulic and hydrological model testing project particularly in flood mitigation study and hydraulic structure. He had carried out numerous physical modelling for many rivers, dam and coastal in Malaysia.

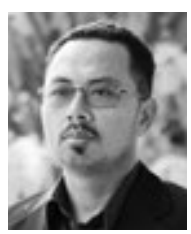

MOHAMAD HIDAYAT JAMAL is a senior lecturer at Universiti Teknologi Malaysia (UTM). He obtained his PhD in the field of coastal engineering in 2011 from University of Plymouth, UK. He has been working at UTM since 2002. He is serving the School of Civil Engineering, Faculty of Engineering, UTM. He is also a member of Center for Coastal and Ocean Engineering (COEI), Research Institute for Sustainable Environment (RISE), UTM. He is a Professional Engineer (BEM), Chartered Engineer (Engineering Council, UK), Chartered Marine Engineer (IMarEST), Certified Professional in Erosion and Sediment Control (CPESC) and professional Technologist (MBOT).

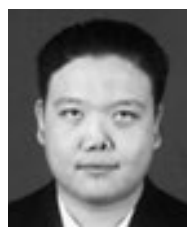

MOHD KAMARUL HUDA SAMION holds a Master degree in Civil Engineering (Hydraulic and Hydrology) from Universiti Teknologi Malaysia, Johor, Malaysia, in 2006. He is currently Senior Research Officer at Makmal Hidraulik dan Instrumentasi, the National Hydraulic Research Institute of Malaysia (NAHRIM) since 2007. He is involved in many physical and numerical modelling projects, including hydraulic model design and analysis.

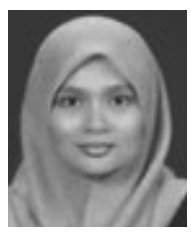

ERNIE ABD MANAN received her Master's degree in Civil Engineering (Water Resources) from Universiti Teknologi MARA, Shah Alam, Selangor, Malaysia in 2012. Previously, she was a Technical Support Officer at HR Wallingford Asia Sdn Bhd in 2013 and joined the National Hydraulic Research Institute of Malaysia (NAHRIM) in 2014. Her current research interests include major engineering disciplines, such as hydrology and hydraulic modeling.

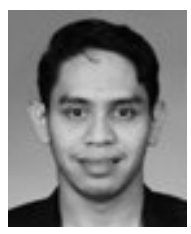

AHMAD FARHAN HAMZAH received PhD in Civil Engineering from Universiti Tun Hussein Onn Malaysia, Johor, Malaysia in 2017. His current research interests include major civil engineering disciplines, materials, and structures. He is a graduate of the Institute of Engineer Malaysia (IEM), the Board of Engineers Malaysia (BEM) and a professional technologist of the Malaysia Board of Technologists (MBOT). 